\title{
Hot spots and trends in knee revision research since the 21st century: a bibliometric analysis
}

\author{
Kelei Zhai, Weifeng Ma, Tao Huang \\ Department of Orthopedics, the First Affiliated Hospital of China Medical University, Shenyang, China \\ Contributions: (I) Conception and design: T Huang; (II) Administrative support: T Huang; (III) Provision of study materials or patients: K Zhai; (IV) \\ Collection and assembly of data: K Zhai, W Ma; (V) Data analysis and interpretation: K Zhai, W Ma; (VI) Manuscript writing: All authors; (VII) \\ Final approval of manuscript: All authors. \\ Correspondence to: Tao Huang. No.155 Nanjingbei Street, Shenyang, China. Email: huangtao@cmu.edu.cn.
}

Background: With the popularization of knee replacement surgery in the treatment of the advanced lesions of knee joint, the amount of knee revision surgery is increasing unceasingly. Meanwhile, the continuous introduction of new clinical concepts and new technology poses a challenge to researchers and surgeons. Our study aims to inform the future scientific research and clinical treatment, by investigating the hot spots and trends of the knee revision research field with the method of bibliometric analysis.

Methods: Publications on knee revision included in the database of Web of Science Core Collection (WoSCC) between 2000 and 2018 were reviewed and MeSH terms of them were extracted from PubMed. Online bibliometric analysis website (http://bibliometric.com/), two pieces of software called "CiteSpace" and "Bibliographic Item Co-Occurrence Matrix Builder" (BICOMB) were used to analyze the publications reviewed at quantitative level. Another piece of software called "gCLUTO", was used to investigate the hot spots with visualization techniques at qualitative level.

Results: A total of 906 publications were retrieved between 2000 and 2018. There is an increasing number of publications, from 15 in 2000 to 86 in 2018. Fournal of Artbroplasty is the leading journal which has the most publications on knee revision. The United States has been the biggest contributor. Mayo Clinic became the leader among the institutions which have conducted correlational researches. David G. Lewallen, Robert L. Barrack and Michael A. Mont should be regarded as the scholars who have made outstanding contribution. Hot spots were summed up in six clusters, respectively, the solutions for infection, prostheses, the adverse effects, the surgical techniques, epidemiological characters, and the pathophysiology of the revision knee.

Conclusions: We found a growing trend in knee revision research and extracted the most contributive researchers, institutions, countries, journals, and most-cited articles worldwide. The solutions for complications, surgical applications and analysis for epidemiological characters have been the hot spots. Multi-disciplinary integration is becoming the time-trend of hot spots. Minimally invasive and navigation are directions of revision surgery. They together constitute a solid foundation and set up a fingerpost for the future scientific research and clinical treatment.

Keywords: Knee revision; hot spots; trends; bi-clustering co-word analysis; visualization

Submitted May 15, 2020. Accepted for publication Dec 04, 2020.

doi: 10.21037/atm-20-3969

View this article at: http://dx.doi.org/10.21037/atm-20-3969 


\section{Introduction}

Joint replacement-honored as an epoch-making operation (1), is a most effective treatment method for the advanced lesion of knee joint. It mainly aims to release the pain thoroughly, correct the alignment and improve the ROM (range of motion) of joint through replacing the broken cartilage and osteophyte on the joint surface with artificial materials. With the development of global population aging and people's demand of higher living quality, the amount of knee replacement surgery is increasing by years. One retrospective study noticed a nearly 27 -fold increase in total knee arthroplasty (TKA) utilization rates in the past decade between 18 different countries (2). However, the artificial prosthesis is not a permanent choice. According to a retrospective survey conducted by Mayo Clinic in 2011, the fifteen-year survival of different prostheses is about $77 \%$ to $90 \%$ (3). A variety of postoperative complications at short-term or long-term may appear, which will result in loss of joint function and even amputation or death if not be disposed in time. Therefore, it is of great significance to conduct knee revision properly and timely.

Revision refers to an operation in which at least one component of the prosthesis need to be replaced, including femoral, patellar, tibial components and the polyethylene line (4). Recently, the number of revision cases has increased a lot, which owes greatly to the rapid increase of primary knee replacement (5). One prospective study predicted that the revision rate in 2030 will be 6 times higher than that of 2005 (6). Meanwhile, new technology and clinical concepts have been introduced continually. Based on that, the hot spots and trends in knee revision research field also have changed over years, which poses a challenge to researchers and surgeons. Groups of scholars and professors have made great efforts and many papers have been published so far, though, lack of a summative review. Therefore, we think it is very essential to make a comprehensive review of this area, from which the new comers as well as the old stagers in this research area can benefit a lot.

Bibliometrics is an interdisciplinary science that uses mathematical and statistical methods to quantitatively analyze all knowledge carriers, especially for scientific publications (7). It plays an important role in revealing the law of the publications and predicting the future direction of the discipline. The co-word analysis method was first described in detail in the middle and late 1970s by French bibliographers. Since then, co-word analysis has been widely used in many fields. Researchers use the basic principles of the co-word method to summarize the hotspots of the research field, to analyze the development process, characteristics of the disciplines horizontally and vertically, to reveal the relationship between the fields or disciplines, to reflect the dynamic and static structures of the research level of a certain subject and its development history, and so on. Till now, it has developed into a discipline with variable statistical analysis methods for different research requirements, including cluster analysis, factor analysis, multi-variate analysis, multi-dimensional scaling analysis and so on. In recent years, bi-clustering analysis has been more popular in the field of bibliometrics. For example, the research trend of the use of stent implantation in the pancreatic diseases has been predicted by Zhu et al. with the method of bi-clustering analysis (8). Another latest bibliometric study on scoliosis research also applied biclustering analysis (9).

Knee revision has always been one of the top-intractable issues for researchers and surgeons, but there was no bibliometric study on it. Our research aims to provide an integrated appraisement of the scientific payoffs of knee revision since the $21^{\text {st }}$ century through co-word biclustering analysis. By identifying the hot spots and trends, we hope that our findings might constitute a solid foundation and set up a fingerpost to inform the future research and clinical treatment on knee revision.

\section{Methods}

\section{Data collection and materials preparation}

On March 16th,2020, publications on knee revision included in the database of Web of Science Core Collection (WoSCC) between January 1st, 2000 and December 31st, 2018 were retrieved. The search command was "Knee revision" OR "Revision total knee revision" OR "Revision TKA", which was under the "basic search" feature and the "title" category. Only articles and reviews were reserved. Then we exported the full record and cited references of them to text-format files, which were prepared to be imported into "CiteSpace (V5.6.R3)" and an online bibliometric analysis website (http://bibliometric.com/) for bibliometric analysis. All of the publications were saved as XML-format files from PubMed, which can be utilized for co-word bi-clustering analysis according to the $\mathrm{MeSH}$ words (10). They were prepared to join in another piece of software "Bibliographic Item Co-Occurrence Matrix Builder" (BICOMB) to sum up hot spots (11). 


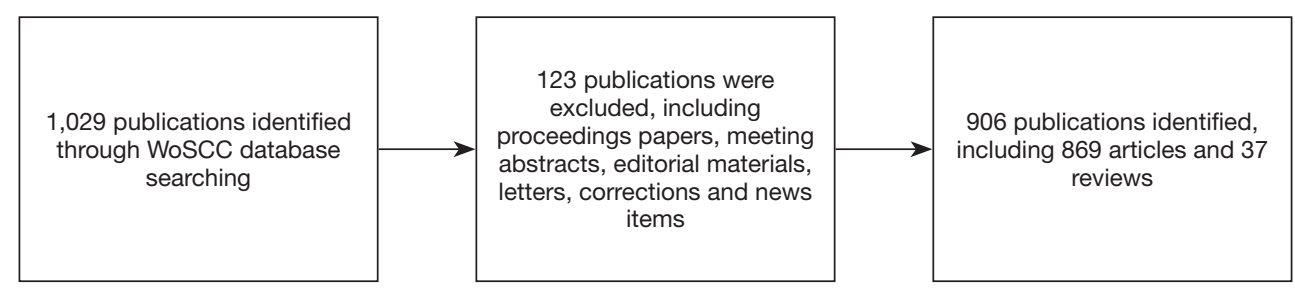

Figure 1 Flow chart of literature screening.

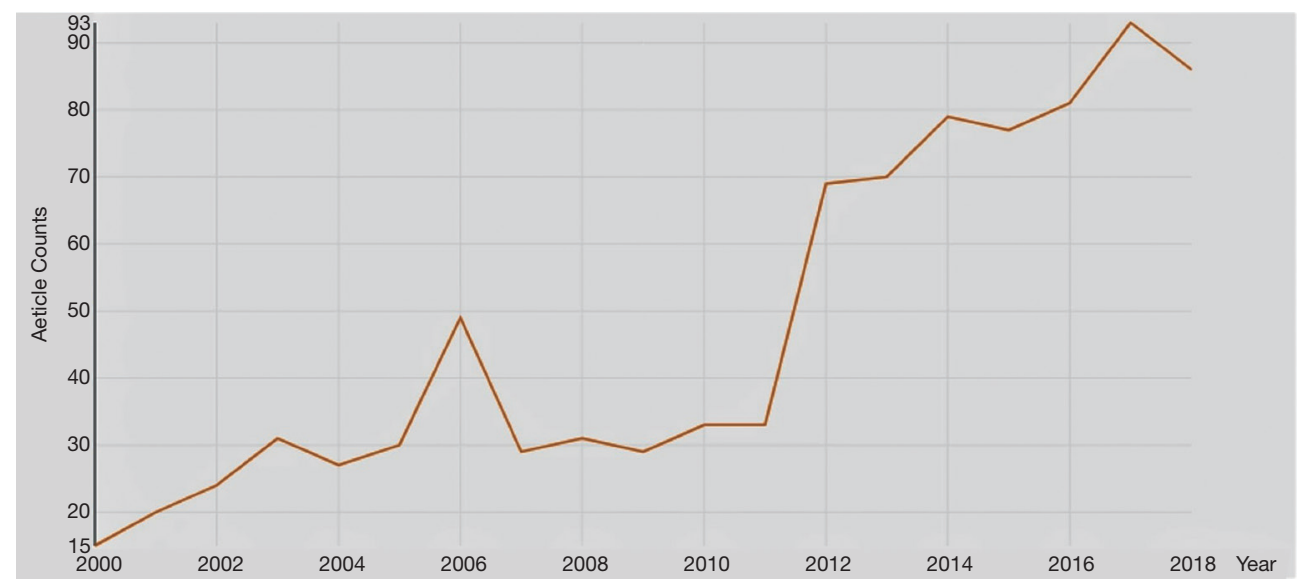

Figure 2 The number of articles on knee revision published from 2000 to 2018.

\section{Statistical analysis}

The online bibliometric analysis website (http:// bibliometric.com/) was used to calculate the quantity of the publications in different views, such as years, countries and authors, the tendencies of which would come out as visualization results. Citespace was used to analyze the collaboration network of the journals, authors, countries and institutions as well as the top cited articles with a visualized presentation (12). To further analyze the scientificity of the study, the latest impact factor (IF) and the citation number of the retrieved articles were checked.

To investigate the hot spots of knee revision, we introduced the methods of co-word bi-clustering analysis, which is applied to identify the relationship between the articles and the high frequency words. BICOMB was utilized to figure out the proportion of the frequency permutations of the MeSH words in the retrieved publications. Meanwhile, we could get a co-word matrix of high-frequency MeSH words based on the G-index algorithm, which was prepared to be imported into "gCLUTO", v1.0 (13). gCLUTO is a piece of software specifically for visually analyzing the co-word matrix, from which research hotspots could be found by clustering the $\mathrm{MeSH}$ words and represented as a mountain visualization. In order to obtain an optimal map, we kept moderating the number of the clusters. Finally, the approximate number came out as six and we successfully established the fundamental framework with comprehensive contents of our study on knee revision.

\section{Results}

\section{Distribution of publications}

\section{Overall distribution}

A total of 906 publications on knee revision research, comprising 869 articles and 37 reviews recorded by the database of WoSCC, were retrieved finally (Figure 1). Generally speaking, it took on an increasing trend in the annual number of the publications from 2000 to 2018, which rose from 15 in 2000 to 86 in 2018. There particularly appeared an explosive growth in 2012 (Figure 2).

\section{Distribution by countries and institutions}

Based on online bibliometric analysis, these publications 
Table 1 The top 10 countries or regions and institutions that published the most articles on knee revision

\begin{tabular}{|c|c|c|c|c|c|c|}
\hline Rank & Country/region & Article counts & Institutions & Article counts & Institutions & Cited counts \\
\hline 3 & UK & 100 & Hosp Special Surg & 32 & Exponent Inc & 528 \\
\hline 2 & Germany & 85 & Rush Univ & 25 & Univ Calif San Francisco & 227 \\
\hline 4 & Canada & 54 & Univ Calif San Francisco & 24 & Univ Minnesota & 211 \\
\hline 6 & Italy & 32 & Exponent Inc & 20 & Tulane Univ & 160 \\
\hline 7 & Netherlands & 30 & Univ Penn & 17 & Univ Western Ontario & 134 \\
\hline 8 & China & 29 & Thomas Jefferson Univ & 16 & Univ British Columbia & 123 \\
\hline 9 & Denmark & 26 & Univ Minnesota & 16 & Mt Sinai Hosp & 118 \\
\hline
\end{tabular}

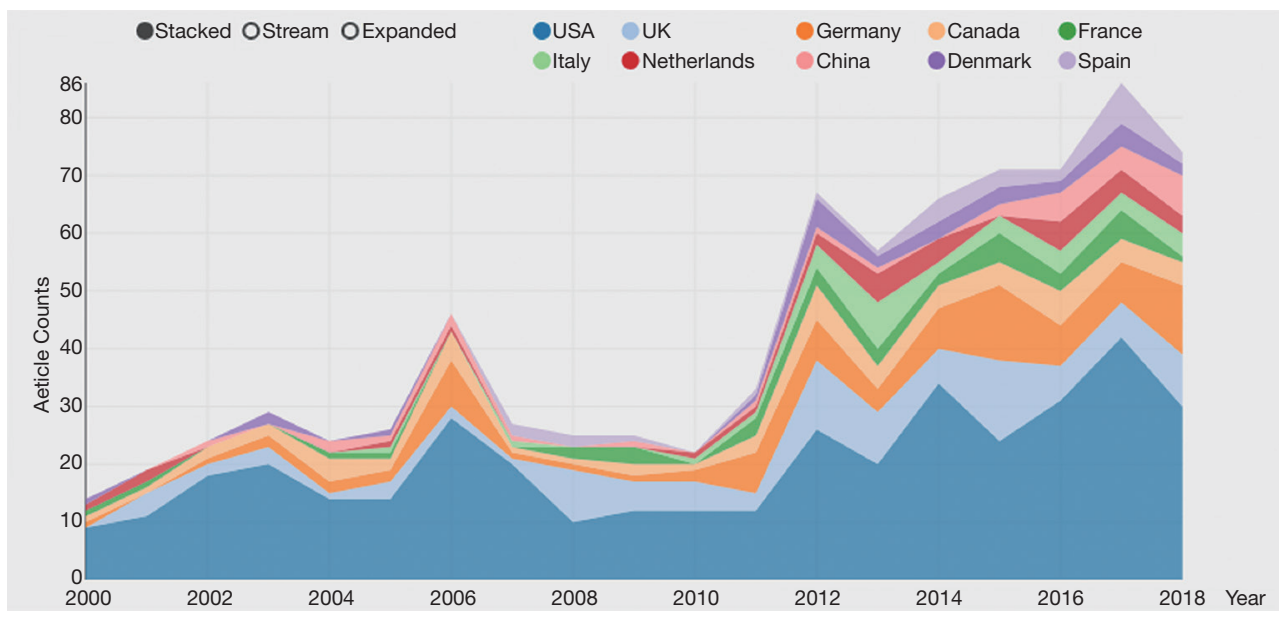

Figure 3 The trend of the top 10 countries/regions that published the most articles from 2000 to 2018.

on knee revision are stemmed from 32 different countries and 1,030 different institutions. The top 10 countries/ regions and institutions are listed in Table 1 and the trend of the top 10 countries/regions is shown in Figure 3. Till now, the United States $(n=387)$ ranked the No. 1 country which had the most publications on knee revision, followed by the UK $(n=100)$, Germany $(n=85)$ and Canada $(n=54)$. Mayo Clinic (n=64) and Hosp Special Surg $(n=32)$ head the list of institutions, which indicates that they had make a great effort in this field. To figure out the authority of these institutions, we arranged the cited counts, then Mayo Clinic $(\mathrm{n}=548)$ and Exponent Inc ( $\mathrm{n}=528)$ became the relatively best qualified to speak in the knee revision research field.

The density $(=0.0046)$ of the network map of institutions is very low (Figure 4), which indicates that the cooperation between the institutions should be reinforced. The cooperation between global countries/regions is mapped in Figure 5. The United States and Canada became the closest partners.

There were 111 journals counted associated with the retrieved publications. The top 10 of them were listed in Table 2, accompanied with the latest IF score and H-index. Among the top 10 journals which had the most publications on knee revision, Fournal of Arthroplasty $(\mathrm{n}=219)$ and Clinical Orthopaedics and Related Research $(\mathrm{n}=108)$ played a leading role with a percentage of $36 \%$ approximately of the 906 publications. And Fournal of Bone and Foint Surgery-American Volume owned the highest IF score (4.716), followed by 


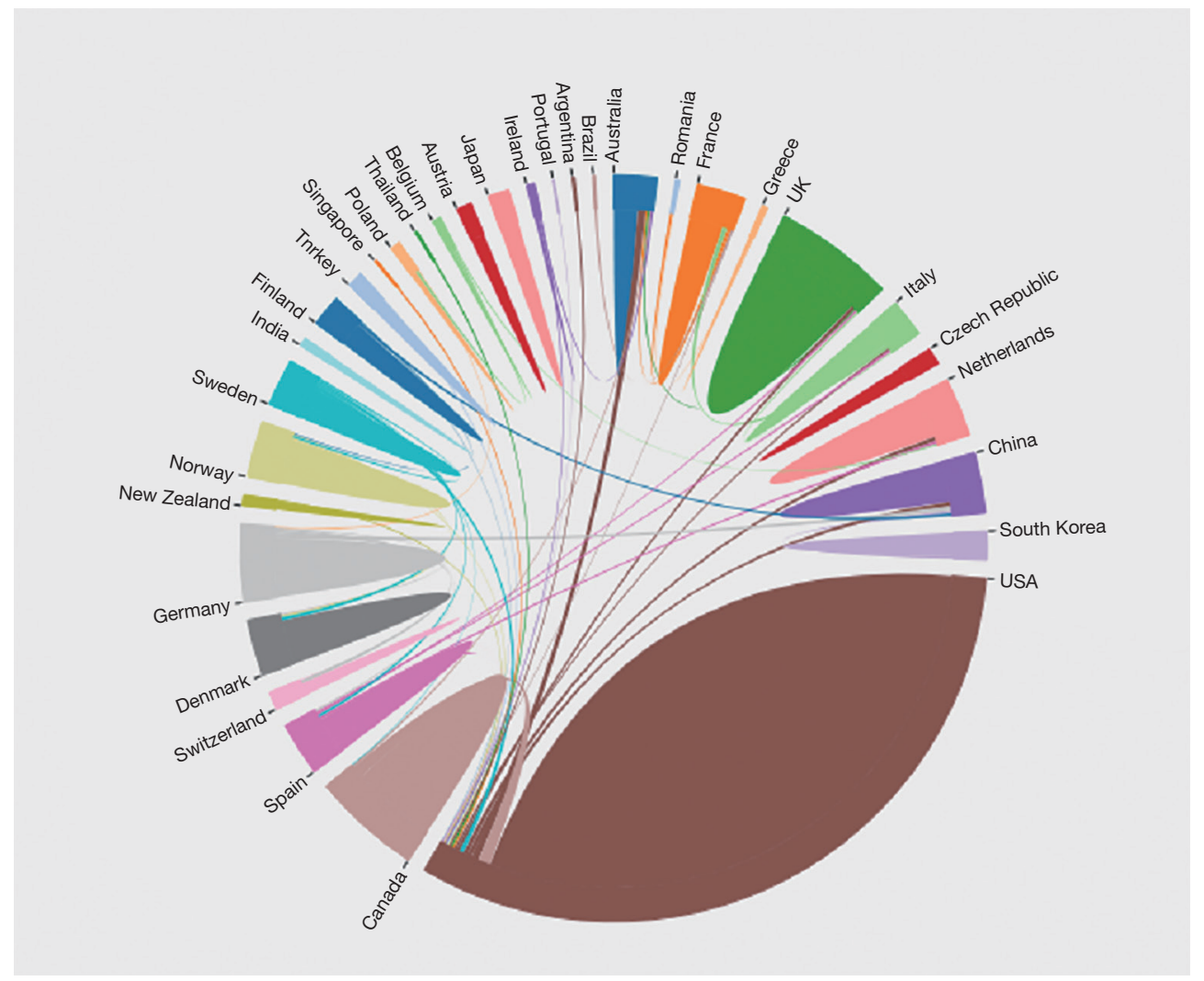

Figure 4 The network map of institutions that involved in knee revision research.

Bone \& Foint fournal (4.301), Clinical Orthopaedics and Related Research (4.154), Journal of Arthroplasty (3.524), ACTA Arthopaedica (3.217) and Knee Surgery Sports Traumatology Arthroscopy (3.149).

\section{Distribution by authors}

There were 2,918 authors counted in this bibliometric study, of which the top 10 productive authors, first authors, corresponding authors and co-cited authors were ranked by the number of articles or citation counts in Table 3.

David G. Lewallen, from Department of Orthopedic Surgery, Mayo Clinic, Rochester, Minnesota, USA, lead the list of the top 10 productive authors with 21 articles published.

Robert L. Barrack, from Department of Orthopaedic Surgery, Washington University School of Medicine, St. Louis, Missouri, USA, became the most-times first author with 9 times.

Michael A. Mont, from Department of Orthopaedic Surgery, Lenox Hill Hospital, New York, USA, was the mosttimes corresponding author with 15 corresponding articles.

Edmund Lau, from Exponent, Inc., Menlo Park,
California, USA, was the most-times cited authors with 312 citation counts.

\section{Distribution by high-cited references}

With the help of Citespace, we were able to analyze the cited information of the retrieved publications. A network map of the correlation of all references of the publications was set up in Figure 6. Depending on the number of citedtimes counted, we made a list of the top 50 high-cited references in Table 4. These references could be considered as strong nodes or pillars of the research field of knee revision. They were the most classic publications with great reference value, from which either the new comers or the old stagers could acquire the research's background, the sum-up of study, the train of thoughts, as well as the new research's methods. Itis also very significant to predict the trend and hot spots of the research field by making a review of the high-cited references.

\section{Research hotspots of knee revision research}

With the utilization of BICOMB, $718 \mathrm{MeSH}$ terms were 


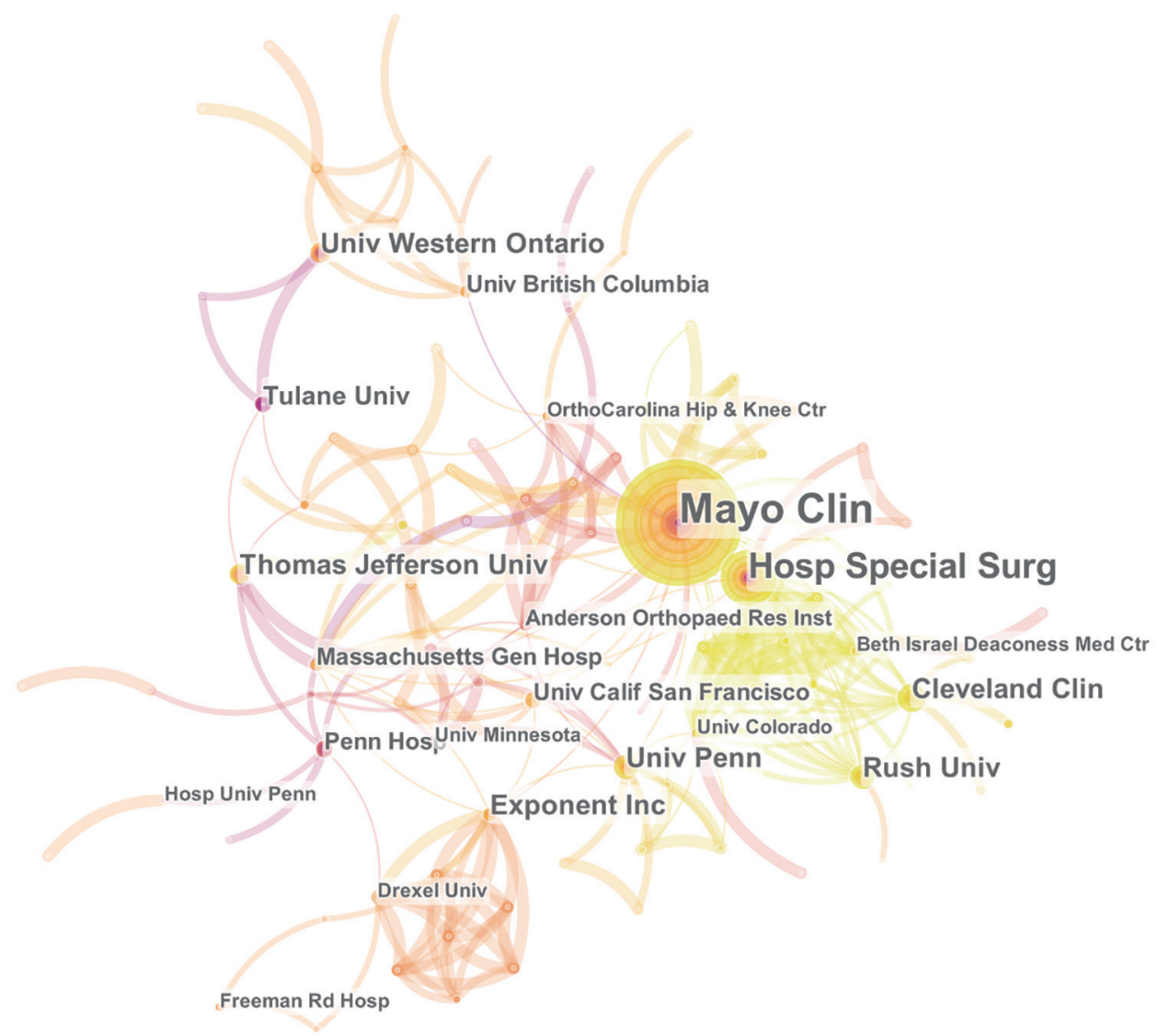

Figure 5 The international cooperation of countries or regions involved in knee revision research.

Table 2 The top 10 most active journals that published articles in knee revision research

\begin{tabular}{|c|c|c|c|c|c|c|c|}
\hline Rank & Journal title & $\begin{array}{l}\text { Article } \\
\text { counts }\end{array}$ & $\begin{array}{l}\text { Percentage } \\
\qquad(\mathrm{N}=906)\end{array}$ & $\begin{array}{l}\text { IF (in } \\
2019)\end{array}$ & $\mathrm{H}$-index & $\begin{array}{c}\text { Total number } \\
\text { of citations }\end{array}$ & $\begin{array}{l}\text { Average number } \\
\text { of citations }\end{array}$ \\
\hline 1 & Journal of Arthroplasty & 219 & $24.17 \%$ & 3.524 & 119 & 1,172 & 5.35 \\
\hline 2 & Clinical Orthopaedics and Related Research & 108 & $11.92 \%$ & 4.154 & 185 & 1,030 & 9.54 \\
\hline 3 & Knee & 57 & $6.29 \%$ & 1.762 & 69 & 262 & 4.60 \\
\hline 5 & Knee Surgery Sports Traumatology Arthroscopy & 46 & $5.08 \%$ & 3.149 & 109 & 132 & 2.87 \\
\hline 6 & International Orthopaedics & 34 & $1.10 \%$ & 2.384 & 77 & 170 & 5.00 \\
\hline 7 & Acta Orthopaedica & 31 & $3.42 \%$ & 3.217 & 100 & 95 & 3.06 \\
\hline
\end{tabular}




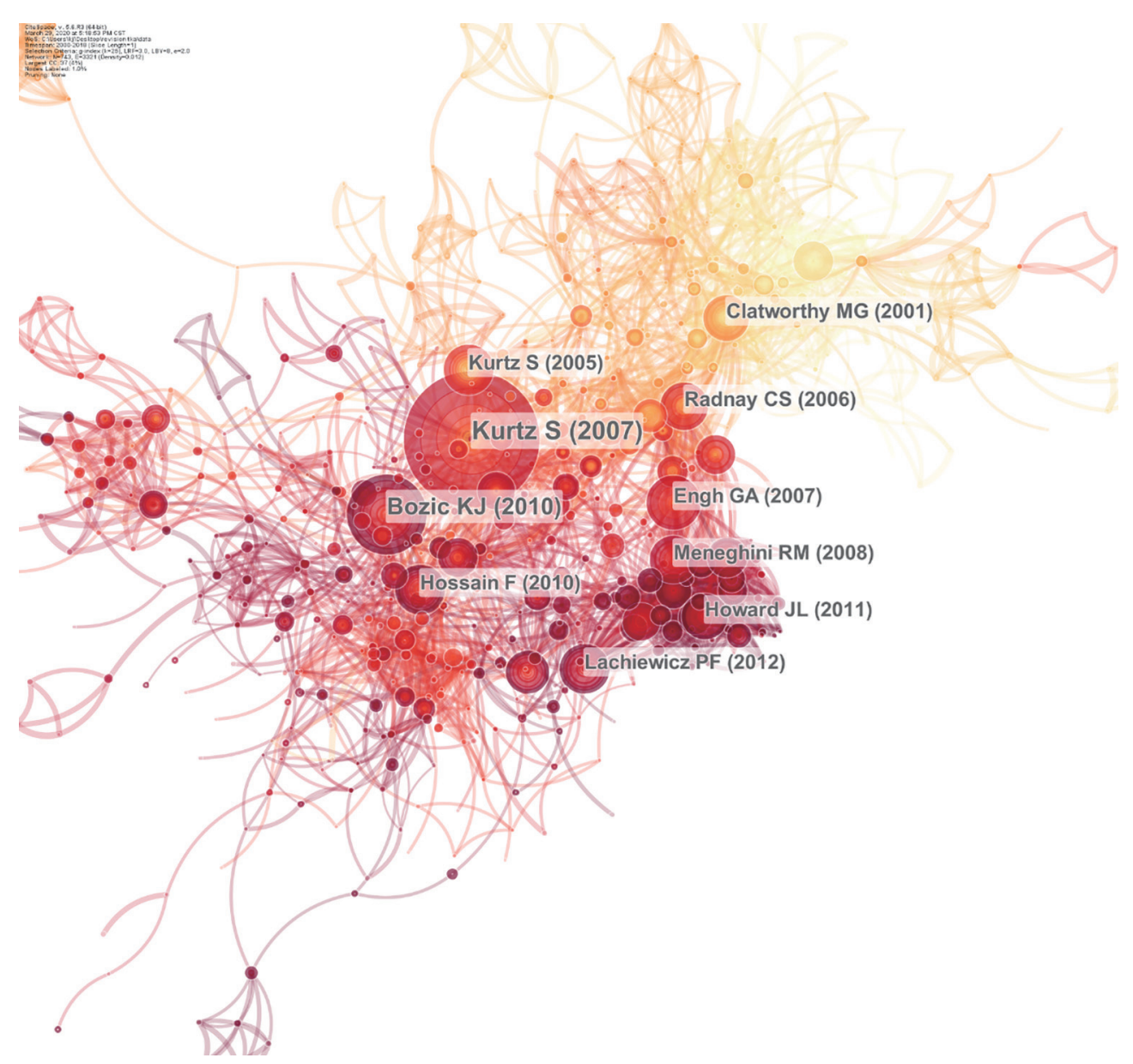

Figure 6 The network map of the correlation of all references of the publications on knee revision.

Table 3 The top 10 productive authors, first authors, corresponding authors and co-cited authors contributed to publications in knee revision research

\begin{tabular}{|c|c|c|c|c|c|c|c|c|}
\hline Rank & Author & $\begin{array}{l}\text { Article } \\
\text { counts }\end{array}$ & $\begin{array}{l}\text { First } \\
\text { author }\end{array}$ & $\begin{array}{l}\text { Article } \\
\text { counts }\end{array}$ & $\begin{array}{l}\text { Corresponding } \\
\text { author }\end{array}$ & $\begin{array}{l}\text { Article } \\
\text { counts }\end{array}$ & $\begin{array}{l}\text { Co-cited } \\
\text { author }\end{array}$ & $\begin{array}{l}\text { Citation } \\
\text { counts }\end{array}$ \\
\hline 1 & Lewallen & 21 & Barrack & 9 & Mont & 15 & Lau & 312 \\
\hline 2 & Parvizi & 20 & Completo & 7 & Parvizi & 11 & Ong & 272 \\
\hline 3 & Mont & 19 & Singh & 6 & Barrack & 9 & Hassen & 258 \\
\hline 6 & Della Valle & 13 & Whiteside & 5 & Singh & 7 & Lewallen & 210 \\
\hline 7 & Masri & 12 & Fehring & 4 & Fehring & 6 & Halpern & 193 \\
\hline 8 & Trousdale & 11 & Sheng & 4 & Trousdale & 6 & Berry & 178 \\
\hline
\end{tabular}


Table 4 The top 50 high-cited references of the publications on knee revision

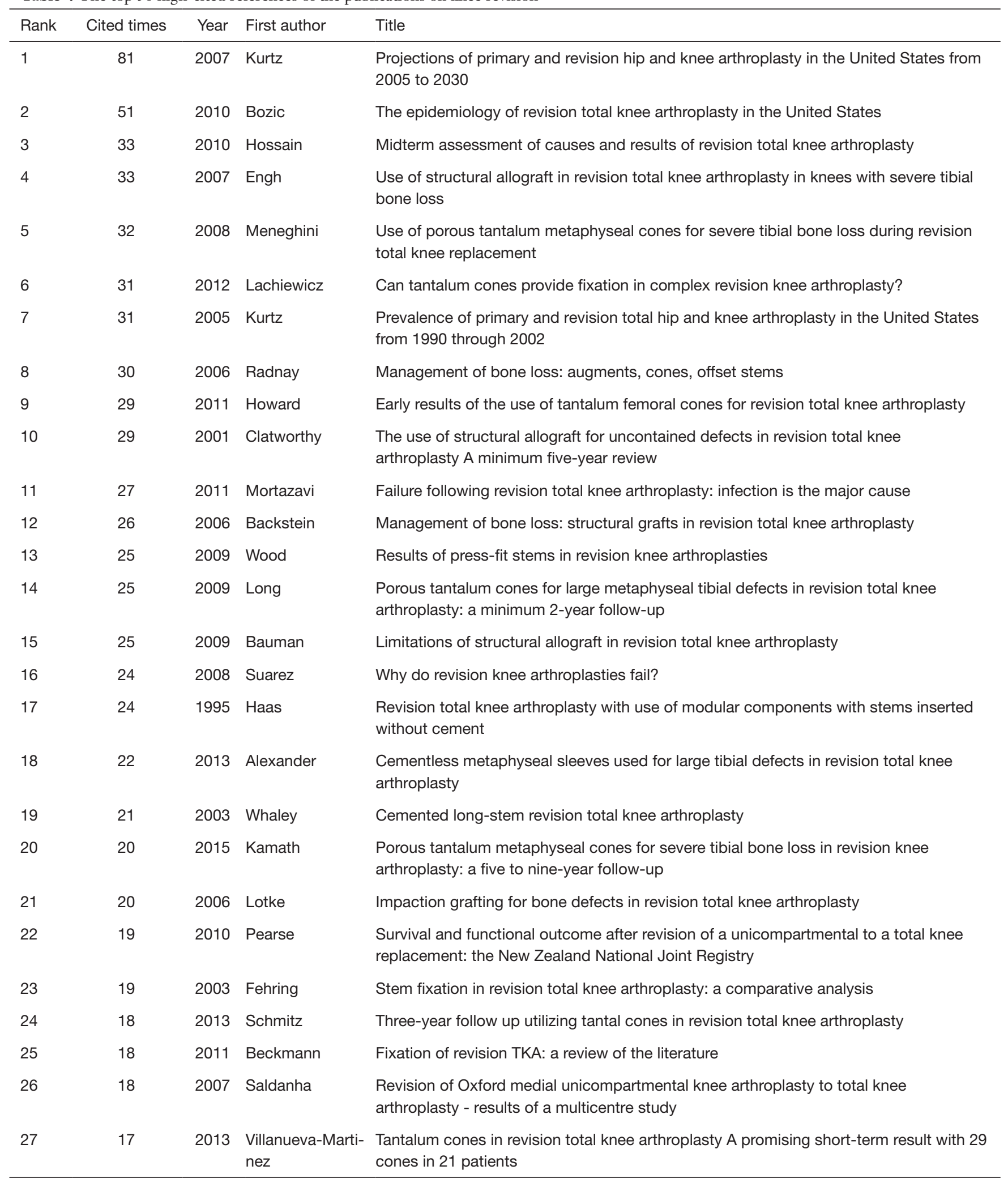

Table 4 (continued) 
Table 4 (continued)

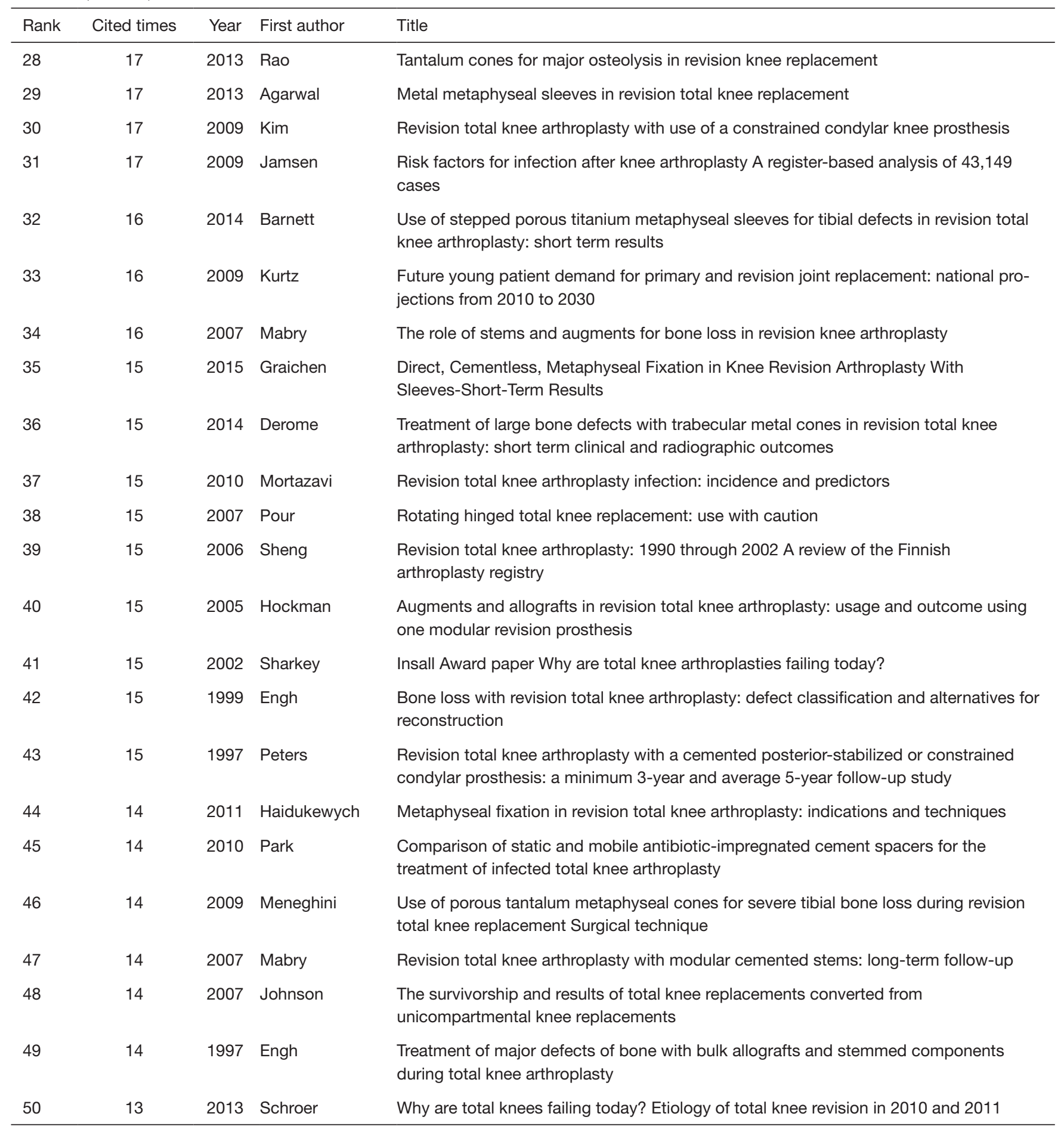

amounted to 3,575 times in total. To avoid too much subjectivity in picking keywords in a bibliometric analysis, we specifically used G-index standard evaluation. It ultimately came out an appearance of more than 11 times that could make a MeSH term relatively high-frequency. 50 high-frequency MeSH terms, occupied $66.29 \%$ 


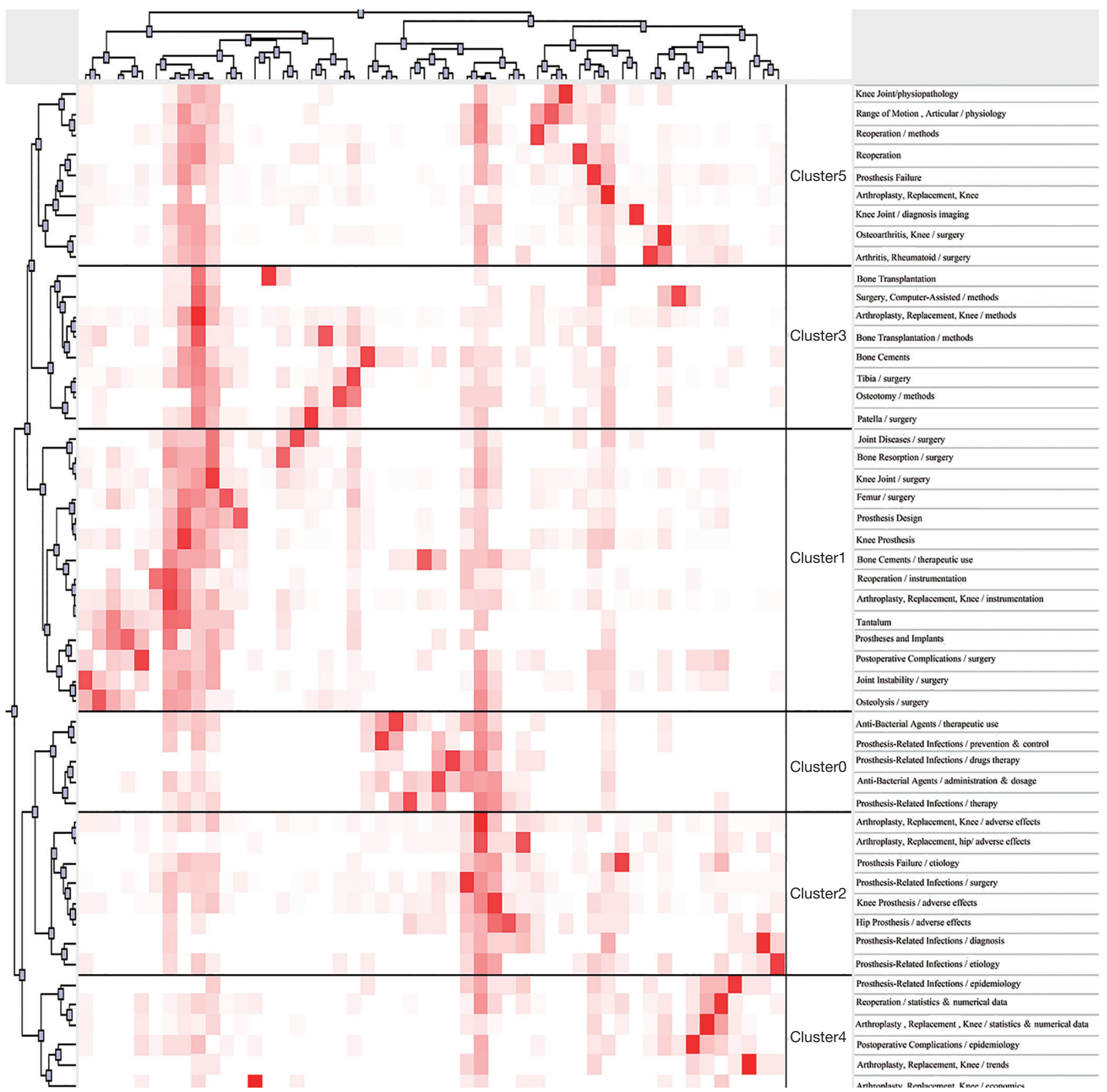

Figure 7 Visualized matrix of biclustering of highly frequent major MeSH terms and PMIDs of articles on knee revision. PMIDs, PubMed Unique Identifiers.

$(2,370 / 3,575)$ of the overall frequency were displayed in Table 5 .

With the use of BICOMB and gCLUTO, different amounts of clusters could be established for hot spots analysis. Then 4 to 10 clusters have been compared to choose an appropriate number of clusters as 6, which has a relatively higher intra-class similarity and a lower inter-class similarity. Matrix visualization was created in Figure 7. The clustering trees formed on the left of the Figure 7 described the internal connection with the corresponding high-frequency $\mathrm{MeSH}$ 
Table 5 Highly frequent major MeSH terms from the included publications on knee revision

\begin{tabular}{|c|c|c|c|c|}
\hline Rank & Major MeSH terms/MeSH subheadings & Frequency & $\begin{array}{l}\text { Proportion of } \\
\text { frequency (\%) }\end{array}$ & $\begin{array}{c}\text { Cumulative } \\
\text { percentage (\%) }\end{array}$ \\
\hline 1 & Arthroplasty, Replacement, Knee/methods & 267 & 7.4685 & 7.4685 \\
\hline 2 & Arthroplasty, Replacement, Knee/adverse effects & 264 & 7.3846 & 14.8531 \\
\hline 3 & Knee Prosthesis & 215 & 6.0140 & 20.8671 \\
\hline 5 & Knee Joint/surgery & 156 & 4.3636 & 29.8462 \\
\hline 6 & Arthroplasty, Replacement, Knee/instrumentation & 122 & 3.4126 & 33.2587 \\
\hline 7 & Knee Prosthesis/adverse effects & 100 & 2.7972 & 36.0559 \\
\hline 8 & Prosthesis Failure & 91 & 2.5455 & 38.6014 \\
\hline 12 & Reoperation/statistics \& numerical data & 50 & 1.3986 & 45.7622 \\
\hline 13 & Arthroplasty, Replacement, Knee/statistics \& numerical data & 46 & 1.2867 & 47.0490 \\
\hline 14 & Reoperation/methods & 42 & 1.1748 & 48.2238 \\
\hline 15 & Femur/surgery & 34 & 0.9510 & 49.1748 \\
\hline 16 & Arthroplasty, Replacement, Hip/adverse effects & 28 & 0.7832 & 49.9580 \\
\hline 17 & Postoperative Complications/epidemiology & 27 & 0.7552 & 50.7133 \\
\hline 18 & Reoperation & 27 & 0.7552 & 51.4685 \\
\hline 24 & Tantalum & 22 & 0.6154 & 55.4965 \\
\hline 25 & Prosthesis Failure/etiology & 21 & 0.5874 & 56.0839 \\
\hline 26 & Prosthesis Design & 21 & 0.5874 & 56.6713 \\
\hline 27 & Osteolysis/surgery & 20 & 0.5594 & 57.2308 \\
\hline 28 & Arthroplasty, Replacement, Knee/economics & 19 & 0.5315 & 57.7622 \\
\hline 29 & Reoperation/instrumentation & 18 & 0.5035 & 58.2657 \\
\hline 30 & Anti-Bacterial Agents/administration \& dosage & 18 & 0.5035 & 58.7692 \\
\hline 31 & Osteotomy/methods & 17 & 0.4755 & 59.2448 \\
\hline 32 & Joint Diseases/surgery & 17 & 0.4755 & 59.7203 \\
\hline 33 & Range of Motion, Articular/physiology & 16 & 0.4476 & 60.1678 \\
\hline 34 & Knee Joint/diagnostic imaging & 16 & 0.4476 & 60.6154 \\
\hline
\end{tabular}

Table 5 (continued) 
Table 5 (continued)

\begin{tabular}{|c|c|c|c|c|}
\hline Rank & Major MeSH terms/MeSH subheadings & Frequency & $\begin{array}{l}\text { Proportion of } \\
\text { frequency (\%) }\end{array}$ & $\begin{array}{c}\text { Cumulative } \\
\text { percentage (\%) }\end{array}$ \\
\hline 35 & Bone Cements & 16 & 0.4476 & 61.0629 \\
\hline 36 & Prosthesis-Related Infections/prevention \& control & 15 & 0.4196 & 61.4825 \\
\hline 37 & Prosthesis-Related Infections/etiology & 15 & 0.4196 & 61.9021 \\
\hline 40 & Bone Transplantation & 14 & 0.3916 & 63.1049 \\
\hline 41 & Anti-Bacterial Agents/therapeutic use & 13 & 0.3636 & 63.4685 \\
\hline 42 & Prosthesis-Related Infections/diagnosis & 13 & 0.3636 & 63.8322 \\
\hline 46 & Prostheses and Implants & 11 & 0.3077 & 65.0629 \\
\hline 47 & Prosthesis-Related Infections/epidemiology & 11 & 0.3077 & 65.3706 \\
\hline 48 & Hip Prosthesis/adverse effects & 11 & 0.3077 & 65.6783 \\
\hline 49 & Prosthesis-Related Infections/drug therapy & 11 & 0.3077 & 65.9860 \\
\hline 50 & Bone Transplantation/methods & 11 & 0.3077 & 66.2937 \\
\hline
\end{tabular}

terms on the right side. Transverse lines separated them into 6 clusters, which sequentially were cluster $5,3,1,0$, 2, 4 from top to bottom. The clustering trees formed on the top of the Figure 7 reflected the relationships among publications, which were one-one correspondence to $\mathrm{MeSH}$ term on the right side. Different colors stand for different values in the matrix. Deeper red represents more times of the appearance of $\mathrm{MeSH}$ terms in a publication, while white is opposite. Meanwhile, three-dimentional landform map was also created to visualize the matrix of $\mathrm{MeSH}$ terms of the retrieved publications (Table 6). Each cluster with its number was displayed as a mountain peak in the map (from 0 to 5 , a total of 6 clusters) (Figure 8). The curve of each mountain peak was a Gaussian curve, which could approximately reflect the distribution of the data in the associated cluster by its position, volume, height, and color. Position represents the intra-cluster similarity. Height reflects the inter-cluster similarity, where exists a positive correlation. There also exists a positive correlation between the volume and the amount of high-frequency $\mathrm{MeSH}$ terms inside the cluster. And only the color at the top of the peak is meaningful, which reveals the inter-cluster standard deviation. Red means low deviation, while blue means high deviation.

Through the in-depth mining of publications, we identified the themes of all the clusters. They were, respectively:

(I) The solutions for infection associated to knee revision (Cluster 0);

(II) The prostheses for revision (Cluster 1);

(III) The adverse effects of revision (Cluster 2);

(IV) The surgical techniques for revision (Cluster 3);

(V) The epidemiological characters of revision (Cluster 4);

(VI) The pathophysiology of the revision knee (Cluster 5).

\section{Discussion}

We found a growth trend of the researches on knee revision since the $21^{\text {st }}$ century with the application of the scientific statistical analysis. The analysis depended on the online bibliometric analysis website (http://bibliometric.com/), two pieces of software "CiteSpace" and "BICOMB". We made our search strategy broad to minimize omissions and to have a relatively comprehensive sets of articles so that the MeSH terms of them can map the hot spots and trends 
Table 6 Highly frequent major MeSH terms/MeSH subheadings_-PMIDs of source publications matrix

\begin{tabular}{|c|c|c|c|c|c|c|}
\hline No. & Major MeSH terms/MeSH subheadings & \multicolumn{5}{|c|}{ PubMed Unique Identifiers of source publications } \\
\hline 1 & Arthroplasty, Replacement, Knee/methods & 0 & 0 & 1 & $\ldots$ & 1 \\
\hline 2 & Arthroplasty, Replacement, Knee/adverse effects & 0 & 0 & 0 & $\ldots$ & 0 \\
\hline 3 & Knee Prosthesis & 0 & 0 & 0 & $\ldots$ & 0 \\
\hline$\ldots$ & $\cdots$ & $\ldots$ & $\ldots$ & $\cdots$ & $\cdots$ & $\ldots$ \\
\hline 49 & Prosthesis-Related Infections/drug therapy & 0 & 0 & 0 & $\ldots$ & 0 \\
\hline 50 & Bone Transplantation/methods & 0 & 0 & 0 & $\ldots$ & 0 \\
\hline
\end{tabular}

PMIDs, PubMed Unique Identifiers.

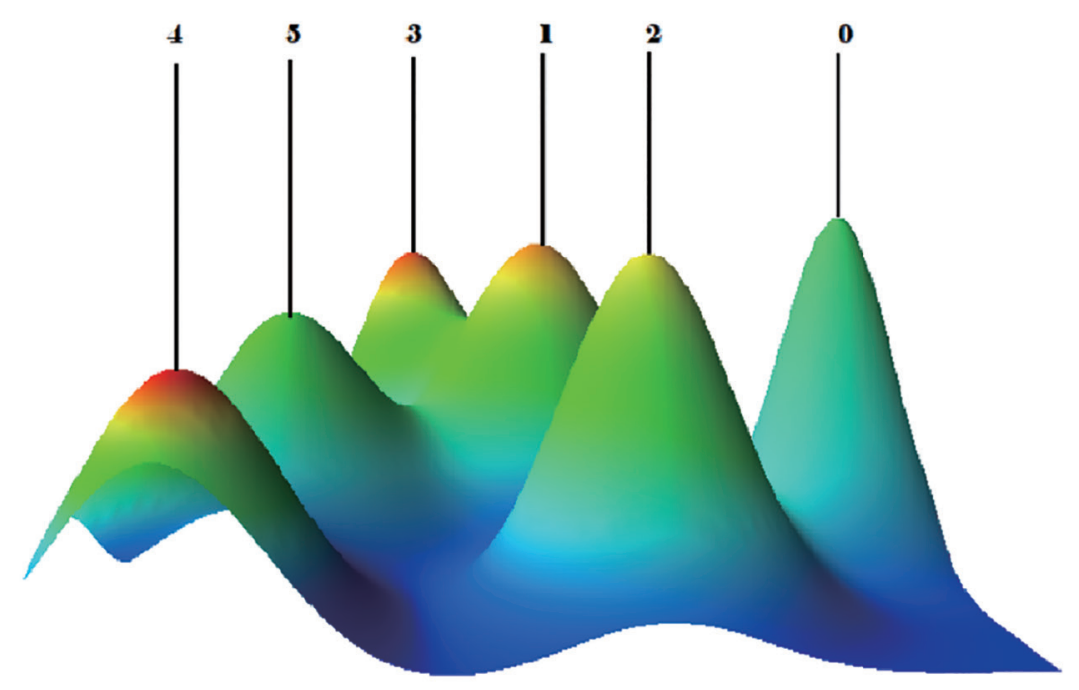

\begin{tabular}{|l} 
Cluster \\
Anti-Bacterial Agents / therapeutic use \\
Prosthesis-Related Infections / prevention \& control \\
Prosthesis-Related Infections / drug therapy \\
Anti-Bacterial Agents / administration \& dosage \\
Prosthesis-Related Infections / therapy \\
Joint Diseases / surgery \\
Bone Resorption / surgery \\
Knee Joint / surgery \\
Femur / surgery \\
Prosthesis Design \\
Knee Prosthesis \\
Bone Cements / therapeutic use \\
Reoperation / instrumentation \\
Arthroplasty, Replacement, Knee / instrumentation \\
Tantalum \\
Prostheses and Implants \\
Postoperative Complications / surgery \\
Joint Instability / surgery \\
Osteolysis / surgery \\
\hline Arthroplasty, Replacement, Knee / adverse effects \\
Arthroplasty, Replacement, Hip / adverse effects \\
Prosthesis Failure / etiology \\
\hline Prosthesis-Related Infections / surgery \\
Knee Prosthesis / adverse effects \\
Hip Prosthesis / adverse effects \\
Prothesis-Related Infections / diagnosis \\
Prothesis-Related Infections / etilogy \\
Bone Transplantation \\
Surgery, Computer-Assisted / methods \\
Arthroplasty, Replacement, Knee / methods \\
Bone Transplantation / methods \\
Bone Cements \\
Tibia / surgery \\
Osteotomy / surgery \\
Patella / surgery \\
Prosthesis-Related Infections / epidemiology \\
Reoperation / statistics \& numercial data \\
Arthroplasty, Replacement, Knee / statistics \& numercial data \\
Postoperative Complications / epidemiology \\
Arthroplasty, Replacement, Knee / trends \\
Arthritis, Rheumatoid / surgery \\
Arthroplasty, Replacement, Knee / economics \\
Knee Joint / physiopathology \\
Range of Motion, Articular / physiology \\
Reoperation / methods \\
Reoperation \\
Prosthesis Failure \\
\hline
\end{tabular}

Figure 8 Mountain visualization of biclustering of highly frequent major MeSH terms and articles on knee revision. 
more efficiently. Similar MeSH terms are identified and divided into different clusters by gCLUTO. Through the process above, a systemic analysis framework on the hot spots and trends of knee revision was set up.

Cluster 0 relates to the solutions for infection associated to knee revision. Infection is the major cause of revision (4), which must be solved. The exploration and controversy of treatment for infection have never stopped.

The selection of opportunity and treatment method should be placed into priority. In clinic, two-stage revision has long been regarded as the golden criterion before. However, with the development of clinic technique, there are increasing doubts on the drawbacks, such as twice operations at least, poor functional activities between the two stages and more costs. Based on that, new treatment methods were applied and the curative effects were observed, for example, debridement with prosthesis retention and anti-biotherapy (14). However, different treatment methods have their unique advantages. To some extent, the selection can be up to the type of infection (15).

Great efforts have been paid in the choice, course, and administration of the antibiotics. As early as 2001, Walenkamp GH reviewed the applications of absorbable gentamicin-loaded collagen and non-absorbable gentamicinloaded bone cement in knee revision (16). In 2009, Chiu and Lin verified the effectiveness of vancomycin impregnated cement and in 2015 (17), low-dose vancomycin through intraosseous regional administration was applied to prevention, which achieves tissue concentrations at a higher level than systemic administration (18). Lately, Teicoplanin has become an efficient drug for antibiosis in spacers (19). Otherwise, five-day course of antibiotics appeared to control the recurrent infection better than one-day course (20).

Different spacers have been extensively tried and compared in two-stage infective revision, such as the gentamicinloaded bone cement (21), the PROSTALAC spacer (22) and so on. The utilization of spacers can reduce pain, improve life quality between the two stages and it also make it easier to implant prostheses again (23). Compared with static spacers, articulating spacers can increase ROM, promote reimplantation, reduce reinfection rate and bone loss (24).

Cluster 1 relates to the prostheses for revision. The prosthesis is the most pivotal point of the surgery, which also costs the most. An ideal prosthesis needs appropriate function, rigid fixation, and a long-term durability. It has long been difficult to balance the conformity, constraint, kinematics, and contact stress in the process of prosthetic design. Especially for bone defects, distinguishing revision from primary arthroplasty, there have been many designs. On the basis of the classification system created by Anderson Orthopaedic Research Institute, different treatment options can be adapted to varying degrees of defects. Recently, tantalum cones have been extensively tested in clinic and become an efficient and effective option in joint stabilization at short-term as well as mid-term follow-up $(25,26)$. And there exists an evolution trend that new cones will have the advantage of varying in sizes for accommodating different bone defects and minimizing the further bone loss (27).

As for constraint, rotating hinge prosthesis and constrained condylar prosthesis are two research points (28-31). The comparison between the outcomes of the two has never stopped and the controversy still exists $(32,33)$.

In addition, there are many other designs developed constantly for different use. Some researchers found that the modular offset coupler with femoral stalk in revision improved not only the posterior condyle offset, but also the alignment, compared to the modular straight stalk (34). Others have set the shape and length of the prosthesis as research objects in recent years (35-37). An intraoperatively moulded PMMA cement-prostheses-like spacer with and lower friction, better stability, higher comfort and a better range of motion has been developed (38).

Cluster 2 relates to the adverse effects of revision. The abrasion of articulating spacers happens within 6 weeks, which will do bad to new prosthesis (39). Reinfection outcome has been analyzed systemically, with a similar result in one-stage and two-stage revision (40). And the availability of new biomarkers like procalcitonin and IL-6 were effective in anti-infection around revision, apart from traditional biomarkers (41). A recent study pointed out full functional recovery needs very long time after knee revision surgery and the improvement of gait is limited when compared to the one achieved at the time of spacer implant (42). And another study found that the bone defects will be more serious under the influence of subluxation of articulating antibiotic spacers (43). Nevertheless, the adverse effects not only influence the preoperative initiatives but extends to Medicare policy, medical resource allocation and social economy (44).

Cluster 3 relates to the surgical techniques for revision. For severe patellar bone loss, Hanssen AD put forward a technique of patellar bone-grafting with satisfying shortterm and mid-term outcomes (45) and Klein et al. reported a gull-wing patellar osteotomy, as a feasible technique in the cases of most severe patellar bone loss (46). Ritschl et al. 
specifically summarized the techniques for different bone defects of the patella in revision surgery (47).

Tibial tubercle osteotomy is a surgical technique that expands surgical field while retains extensor's function compared with quadriceps snip, has gained popularity in knee revision surgery for many years (48). There have been many attempts aiming at improving it. Ethibond sutures was invented by Deane et al. with lower risk of complication than traditional fixation methods (49). Absorbable suture fixation was verified to be a simple and dependable fixation method, which is also affordable (50). Nowadays, the computer-assisted navigation and preoperative software have been introduced to improve the accuracy in revision surgery (51-53).

Cluster 4 relates to the epidemiological characters of revision. Nationwide and worldwide statistical data has been collected to analyze the rate and trends of revision (2,54-56). Recently, a research group established several parametric and non-parametric models to estimate prostheses' survivorship more accurately (57). Another research group analyzed the predictive factors of revision, prosthetic infection and mortality in rheumatoid arthritis patients based on Danish healthcare registers (58). The risk factors of revision have also been analyzed popularly. There were studies supporting that smoking do increases the revision rate after knee arthroplasty $(59,60)$. Glycemic control was given certain attention to reduce the revision rate (61). Obesity is another risk factor which promotes revision with more expenses (62-64). Preoperative opioid use has become a focus associated with higher revision rates recently (65-67).

Cluster 5 relates to the pathophysiology of the revision knee. Knee instability is an important pathological feature in revision cases. Hamilton et al. suggested to develop a test to quantize the instability, not according to subjective clinical assessment by patients' symptoms (68). Vince et al. explained a simple and universally applicable revision technique that balancing the knee first in flexion and then in extension could optimize motion and stability (69). Stiffness is an uncommon but notable pathological feature after total knee arthroplasty. Revision was previously reported as a relatively better management than the limited approaches such as soft tissue release. But the improvement was modest (70-72). However, there has been a marked improvement in a 2-year clinical outcome of severe stiffness cases, with the use of Genesis and Legion stemmed condylar prostheses (73). In 2016, Donaldson et al. even presented a novel technique for improving stiffness, named by "sloppy" revision (74).

However, we realized several potential limitations in this study. Firstly, we only selected original articles and reviews to analyze, so some of the hot spots might be missing. Secondly, the amount of analyzed MeSH terms might affect the result of co-word bi-clustering analysis to some extent, and might not cover the emerging topics of low concern. Thirdly, as the database is constantly updated, the number of articles on knee revision must increase. Therefore, in future research, the bibliometric analysis of knee revision should be combined with more emerging topics and more databases.

\section{Conclusions}

With the utilization of the software and websites for bibliometric analysis, we found a growing trend in publications on knee revision and extracted the most contributive researchers, institutions, countries, journals, and most-cited articles worldwide at quantitative level. They have an internalized understanding of this domain and provide principles and guidelines for global researchers as references.

At the qualitative level, through years of practice and discussion, the academic world has reached a consensus on the etiology and indications of revision and many effective clinical techniques have been tested widely and developed continuously in the perioperative period of revision. But there still exists a lot of room for improvement in the solutions for complications and surgical applications, which have also been the hot spots discussed widely these years. Personalized customization with better biomechanical characteristics may become a trend in the design of prostheses for different patients. Minimally invasive and navigation are two attractive concepts and techniques for surgeons, which are excepted to be further developed in the $21^{\text {st }}$ century. With the continuous renewal of surgical instruments and prosthesis design, the surgery is becoming more reasonable and standardized. The utilization of navigation system, which makes it more precise in prosthesis implantation and joint line adjustment, should be included in the future development of revision surgery. Under the background of big-data era, holistic statistical analyses are in progress for individual risk factors and collective epidemiological characters, which can be seemed as another hot spot. And the combination of medicine and economy in analysis is favourable to deploy medical resource more reasonably. Multi-disciplinary integration, which includes medicine, biomechanics, materials science, computer science, epidemiology, and other science, is becoming the 
time-trend of hot spots. The hot spots will continue to obtain achievements and our study will provide a powerful reference for the future research and clinical treatment on knee revision.

\section{Acknowledgments}

We acknowledge the editors and the anonymous reviewers for insightful suggestions on this work.

Funding: None.

\section{Footnote}

Conflicts of Interest: All authors have completed the ICMJE uniform disclosure form (available at http://dx.doi. org/10.21037/atm-20-3969). The authors have no conflicts of interest to declare.

Ethical Statement: The authors are accountable for all aspects of the work in ensuring that questions related to the accuracy or integrity of any part of the work are appropriately investigated and resolved.

Open Access Statement: This is an Open Access article distributed in accordance with the Creative Commons Attribution-NonCommercial-NoDerivs 4.0 International License (CC BY-NC-ND 4.0), which permits the noncommercial replication and distribution of the article with the strict proviso that no changes or edits are made and the original work is properly cited (including links to both the formal publication through the relevant DOI and the license). See: https://creativecommons.org/licenses/by-nc-nd/4.0/.

\section{References}

1. Learmonth ID, Young C, Rorabeck C. The operation of the century: total hip replacement. Lancet 2007;370:1508-19.

2. Kurtz SM, Ong KL, Lau E, et al. International survey of primary and revision total knee replacement. Int Orthop 2011;35:1783-9.

3. Abdel MP, Morrey ME, Jensen MR, et al. Increased long-term survival of posterior cruciate-retaining versus posterior cruciate-stabilizing total knee replacements. J Bone Joint Surg Am 2011;93:2072-8.

4. Mortazavi SM, Molligan J, Austin MS, et al. Failure following revision total knee arthroplasty: infection is the major cause. Int Orthop 2011;35:1157-64.

5. Kane RL, Saleh KJ, Wilt TJ, et al. Total knee replacement.
Evid Rep Technol Assess (Summ) 2003;(86):1-8.

6. Kurtz S, Ong K, Lau E, et al. Projections of primary and revision hip and knee arthroplasty in the United States from 2005 to 2030. J Bone Joint Surg Am 2007;89:780-5.

7. Demir E, Yaşar E, Özkoçak V, et al. The evolution of the field of legal medicine: A holistic investigation of global outputs with bibliometric analysis. J Forensic Leg Med 2020;69:101885.

8. Zhu X, Niu X, Li T, et al. Identification of research trends concerning application of stent implantation in the treatment of pancreatic diseases by quantitative and biclustering analysis: a bibliometric analysis. PeerJ 2019;7:e7674.

9. Tao L, Zhou S, Tao Z, et al. The publication trends and hot spots of scoliosis research from 2009 to 2018: a 10year bibliometric analysis. Ann Transl Med 2020;8:365.

10. Li F, Li M, Guan P, et al. Mapping publication trends and identifying hot spots of research on Internet health information seeking behavior: a quantitative and co-word biclustering analysis. J Med Internet Res 2015;17:e81.

11. Cui LLW, Yan L, Zhang H, et al. Development of a text mining system based on the co-occurrence of bibliographic items in literature databases. New Technol Lib Inf Ser 2008;8:70-5.

12. Chen C, Song M. Visualizing a field of research: A methodology of systematic scientometric reviews. PLoS One 2019;14:e0223994.

13. Karypis Lab. gCLUTO-graphical clustering toolkit. 2014. Available online: http://glaros.dtc.umn.edu/gkhome/cluto/ gcluto/download

14. Lizaur-Utrilla A, Gonzalez-Parreño S, Gil-Guillen V, et al. Debridement with prosthesis retention and antibiotherapy vs. two-stage revision for periprosthetic knee infection within 3 months after arthroplasty: a case-control study. Clin Microbiol Infect 2015;21:851.e11-7.

15. Chiu FY, Chen CM. Surgical débridement and parenteral antibiotics in infected revision total knee arthroplasty. Clin Orthop Relat Res 2007;461:130-5.

16. Walenkamp GH. Gentamicin PMMA beads and other local antibiotic carriers in two-stage revision of total knee infection: a review. J Chemother 2001;13:66-72.

17. Chiu FY, Lin CF. Antibiotic-impregnated cement in revision total knee arthroplasty. A prospective cohort study of one hundred and eighty-three knees. J Bone Joint Surg Am 2009;91:628-33.

18. Young SW, Zhang M, Moore GA, et al. The John N. Insall Award: Higher Tissue Concentrations of Vancomycin Achieved With Intraosseous Regional Prophylaxis in 
Revision TKA: A Randomized Controlled Trial. Clin Orthop Relat Res 2018;476:66-74.

19. Buyuk AF, Sofu H, Camurcu IY, et al. Can Teicoplanin Be an Effective Choice for Antibiotic-Impregnated Cement Spacer in Two-Stage Revision Total Knee Arthroplasty? J Knee Surg 2017;30:283-8.

20. Claret G, Tornero E, Martínez-Pastor JC, et al. A Prolonged Post-Operative Antibiotic Regimen Reduced the Rate of Prosthetic Joint Infection after Aseptic Revision Knee Arthroplasty. Surg Infect (Larchmt) 2015;16:775-80.

21. Classen T, von Knoch M, Wernsmann M, et al. Functional interest of an articulating spacer in two-stage infected total knee arthroplasty revision. Orthop Traumatol Surg Res 2014;100:409-12.

22. Gooding CR, Masri BA, Duncan CP, et al. Durable infection control and function with the PROSTALAC spacer in two-stage revision for infected knee arthroplasty. Clin Orthop Relat Res 2011;469:985-93.

23. Vecchini E, Micheloni GM, Perusi F, et al. AntibioticLoaded Spacer for Two-Stage Revision of Infected Total Knee Arthroplasty. J Knee Surg 2017;30:231-7.

24. Guild GN, Wu B, Scuderi GR. Articulating vs. Static antibiotic impregnated spacers in revision total knee arthroplasty for sepsis. A systematic review. J Arthroplasty 2014;29:558-63.

25. Derome P, Sternheim A, Backstein D, et al. Treatment of large bone defects with trabecular metal cones in revision total knee arthroplasty: short term clinical and radiographic outcomes. J Arthroplasty 2014;29:122-6.

26. De Martino I, De Santis V, Sculco PK, et al. Tantalum Cones Provide Durable Mid-term Fixation in Revision TKA. Clin Orthop Relat Res 2015;473:3176-82.

27. Kim EG, Patel NK, Chughtai M, et al. Tantalum Cones in Revision Total Knee Arthroplasty. J Knee Surg 2016;29:621-6.

28. Kearns SM, Culp BM, Bohl DD, et al. Rotating Hinge Implants for Complex Primary and Revision Total Knee Arthroplasty. J Arthroplasty 2018;33:766-70.

29. Pour AE, Parvizi J, Slenker N, et al. Rotating hinged total knee replacement: use with caution. J Bone Joint Surg Am 2007;89:1735-41.

30. Vasso M, Beaufils P, Schiavone Panni A. Constraint choice in revision knee arthroplasty. Int Orthop 2013;37:1279-84.

31. Sanz-Ruiz P, Villanueva-Martínez M, Matas-Diez JA, et al. Revision TKA with a condylar constrained prosthesis using metaphyseal and surface cementation: a minimum 6-year follow-up analysis. BMC Musculoskelet Disord
2015;16:39.

32. Hommel H, Wilke K, Kunze D, et al. Constraint choice in revision knee arthroplasty: study protocol of a randomised controlled trial assessing the effect of level of constraint on postoperative outcome. BMJ Open 2017;7:e012964.

33. Fuchs S, Sandmann C, Gerdemann G, et al. Quality of life and clinical outcome in salvage revision total knee replacement: hinged vs total condylar design. Knee Surg Sports Traumatol Arthrosc 2004;12:140-3.

34. Brilhault JM, Ries MD. Influence of offset stem couplers in femoral revision knee arthroplasty: a radiographic study. Knee 2012;19:112-5.

35. Heinecke M, Rathje F, Layher F, et al. The Proximal and Distal Femoral Canal Geometry Influences Cementless Stem Anchorage and Revision Hip and Knee Implant Stability. Orthopedics 2018;41:e369-75.

36. Barry JJ, Thielen Z, Sing DC, et al. Length of Endoprosthetic Reconstruction in Revision Knee Arthroplasty Is Associated With Complications and Reoperations. Clin Orthop Relat Res 2017;475:72-9.

37. Lachiewicz PF, Soileau ES. A 30-mm cemented stem extension provides adequate fixation of the tibial component in revision knee arthroplasty. Clin Orthop Relat Res 2015;473:185-9.

38. Kohl S, Evangelopoulos DS, Kohlhof H, et al. An intraoperatively moulded PMMA prostheses like spacer for two-stage revision of infected total knee arthroplasty. Knee 2011;18:464-9.

39. Fink B, Rechtenbach A, Büchner H, et al. Articulating spacers used in two-stage revision of infected hip and knee prostheses abrade with time. Clin Orthop Relat Res 2011;469:1095-102.

40. Kunutsor SK, Whitehouse MR, Lenguerrand E, et al. Re-Infection Outcomes Following One- And TwoStage Surgical Revision of Infected Knee Prosthesis: A Systematic Review and Meta-Analysis. PLoS One 2016;11:e0151537.

41. Glehr M, Friesenbichler J, Hofmann G, et al. Novel biomarkers to detect infection in revision hip and knee arthroplasties. Clin Orthop Relat Res 2013;471:2621-8.

42. Logoluso N, Nardo A, Anasetti F, et al. Does knee revision after an articulated spacer implant provide normal gait restoration? Knee Surg Sports Traumatol Arthrosc 2016;24:267-72.

43. Lau AC, Howard JL, Macdonald SJ, et al. The Effect of Subluxation of Articulating Antibiotic Spacers on Bone Defects and Degree of Constraint in Revision Knee Arthroplasty. J Arthroplasty 2016;31:199-203. 
44. Kurtz SM, Ong KL, Schmier J, et al. Future clinical and economic impact of revision total hip and knee arthroplasty. J Bone Joint Surg Am 2007;89 Suppl 3:144-51.

45. Hanssen AD. Bone-grafting for severe patellar bone loss during revision knee arthroplasty. J Bone Joint Surg Am 2001;83:171-6.

46. Klein GR, Levine HB, Ambrose JF, et al. Gull-wing osteotomy for the treatment of the deficient patella in revision total knee arthroplasty. J Arthroplasty 2010;25:249-53.

47. Ritschl P, Machacek F, Strehn L, et al. Surgical Techniques for Patella Replacement in Cases of Deficient Bone Stock in Revision TKA. Z Orthop Unfall 2015;153:321-3.

48. Punwar SA, Fick DP, Khan RJK. Tibial Tubercle Osteotomy in Revision Knee Arthroplasty. J Arthroplasty 2017;32:903-7.

49. Deane CR, Ferran NA, Ghandour A, et al. Tibial tubercle osteotomy for access during revision knee arthroplasty: Ethibond suture repair technique. BMC Musculoskelet Disord 2008;9:98.

50. Zonnenberg CB, van den Bekerom MP, de Jong T, et al. Tibial tubercle osteotomy with absorbable suture fixation in revision total knee arthroplasty: a report of 23 cases. Arch Orthop Trauma Surg 2014;134:667-72.

51. Saragaglia D, Marques Da Silva B, Dijoux P, et al. Computerised navigation of unicondylar knee prostheses: from primary implantation to revision to total knee arthroplasty. Int Orthop 2017;41:293-9.

52. Hoffart HE, Dinges H, Kolbeck S, et al. Novel computerassisted method for revision arthroplasty of the knee. World J Orthop 2015;6:821-8.

53. Ochs BG, Schreiner AJ, de Zwart PM, et al. Computerassisted navigation is beneficial both in primary and revision surgery with modular rotating-hinge knee arthroplasty. Knee Surg Sports Traumatol Arthrosc 2016;24:64-73.

54. Pabinger C, Berghold A, Boehler N, et al. Revision rates after knee replacement. Cumulative results from worldwide clinical studies versus joint registers. Osteoarthritis Cartilage 2013;21:263-8.

55. Singh J, Politis A, Loucks L, et al. Trends in revision hip and knee arthroplasty observations after implementation of a regional joint replacement registry. Can J Surg 2016;59:304-10.

56. Delanois RE, Mistry JB, Gwam CU, et al. Current Epidemiology of Revision Total Knee Arthroplasty in the United States. J Arthroplasty 2017;32:2663-8.

57. Aram P, Trela-Larsen L, Sayers A, et al. Estimating an Individual's Probability of Revision Surgery After Knee Replacement: A Comparison of Modeling Approaches Using a National Data Set. Am J Epidemiol 2018;187:2252-62.

58. Cordtz RL, Zobbe K, Hojgaard P, et al. Predictors of revision, prosthetic joint infection and mortality following total hip or total knee arthroplasty in patients with rheumatoid arthritis: a nationwide cohort study using Danish healthcare registers. Ann Rheum Dis 2018;77:281-8.

59. Kapadia BH, Johnson AJ, Naziri Q, et al. Increased revision rates after total knee arthroplasty in patients who smoke. J Arthroplasty 2012;27:1690-5.e1.

60. Nwachukwu BU, Gurary EB, Lerner V, et al. Effect of smoking and soft tissue release on risk of revision after total knee arthroplasty: a case- control study. BMC Musculoskelet Disord 2015;16:245.

61. Roche MW, Law TY, Triplet JJ, et al. Effect of Hypoglycemia on the Incidence of Revision in Total Knee Arthroplasty. J Arthroplasty 2017;32:499-502.

62. Lim CT, Goodman SB, Huddleston JI, et al. Weight Gain After Primary Total Knee Arthroplasty Is Associated With Accelerated Time to Revision for Aseptic Loosening. J Arthroplasty 2017;32:2167-70.

63. Roche M, Law TY, Kurowicki J, et al. Effect of Obesity on Total Knee Arthroplasty Costs and Revision Rate. J Knee Surg 2018;31:38-42.

64. Bieger R, Kappe T, Jung S, et al. Does the body mass index influence the results of revision total knee arthroplasty? $\mathrm{Z}$ Orthop Unfall 2013;151:226-30.

65. Weick J, Bawa H, Dirschl DR, et al. Preoperative Opioid Use Is Associated with Higher Readmission and Revision Rates in Total Knee and Total Hip Arthroplasty. J Bone Joint Surg Am 2018;100:1171-6.

66. Bedard NA, DeMik DE, Dowdle SB, et al. Preoperative Opioid Use and Its Association With Early Revision of Total Knee Arthroplasty. J Arthroplasty 2018;33:3520-3.

67. Starr J, Rozet I, Ben-Ari A. A Risk Calculator Using Preoperative Opioids for Prediction of Total Knee Revision Arthroplasty. Clin J Pain 2018;34:328-31.

68. Hamilton DF, Burnett R, Patton JT, et al. The identification and quantification of instability in a primary total knee replacement prior to revision. Bone Joint J 2014;96-B:1339-43.

69. Vince KG, Droll KP, Chivas D. Your next revision total knee arthroplasty: why start in flexion? Orthopedics 2007;30:791-2.

70. Kim J, Nelson CL, Lotke PA. Stiffness after total knee arthroplasty. Prevalence of the complication and outcomes 
of revision. J Bone Joint Surg Am 2004;86:1479-84.

71. Keeney JA, Clohisy JC, Curry M, et al. Revision total knee arthroplasty for restricted motion. Clin Orthop Relat Res 2005;440:135-40.

72. Haidukewych GJ, Jacofsky DJ, Pagnano MW, et al. Functional results after revision of well-fixed components for stiffness after primary total knee arthroplasty. J

Cite this article as: Zhai $\mathrm{K}, \mathrm{Ma} \mathrm{W}$, Huang $\mathrm{T}$. Hot spots and trends in knee revision research since the 21 st century: a bibliometric analysis. Ann Transl Med 2021;9(5):388. doi: 10.21037/atm-20-3969
Arthroplasty 2005;20:133-8.

73. Heesterbeek PJ, Goosen JH, Schimmel JJ, et al. Moderate clinical improvement after revision arthroplasty of the severely stiff knee. Knee Surg Sports Traumatol Arthrosc 2016;24:3235-41.

74. Donaldson JR, Tudor F, Gollish J. Revision surgery for the stiff total knee arthroplasty. Bone Joint J 2016;98-B:622-7. 